ful marketing, particularly since the market leaders in many countries were drugs with no evidence of benefits in mortality at the time. This may also explain in part why the heaviest use was in France, which had relatively low cardiovascular mortality even before statins were available. Political, cultural, and social issues determine such use as well as medical indications. In view of the public health implications, these merit more specific study in each country.

Contributors: All members of EuroMedStat contributed to data collection and analysis. All named authors helped to draft this article. PF-G is the project coordinator. TW is guarantor for the article.

Funding: This work was funded by the European Commission, which had no role in the design, data collection, data analysis, interpretation, or writing of this report.
Competing interests: EvG has received unrestricted research funds from a company that manufactures a statin.

World Health Organization. European health for all database. Updated January 2003 http://www.euro.who.int/hfadb (accessed 29 Apr 2003).

2 Sudlow C, Lonn E, Pignone M, Ness A, Rihal C. Secondary prevention of ischaemic cardiac events. In: Clinical evidence. Issue 9. London: BMJ Publishing, 2003:166-205.

3 The Euro-Med-Stat Group. Euro-Med-Stat: monitoring expenditure and utilisation of medicinal products in the European Union countries. A public health approach. Eur J Public Health (in press).

4 Larsen J, Vaccheri A, Andersen M, Montanaro N, Bergman U. Lack of adherence to lipid-lowering drug treatment. A comparison of utilization patterns in defined populations in Funen, Denmark and Bologna, Italy. $\mathrm{Br}$ J Clin Pharmacol 2000;49:463-71.

5 Majeed A, Moser K, Maxwell R. Age, sex and practice variations in the use of statins in general practice in England and Wales. J Public Health Med 2000;22:275-9.

(Accepted 26 November 2003)

\title{
Prevalence of asthma and allergy in schoolchildren in Belmont, Australia: three cross sectional surveys over 20 years
}

Brett G Toelle, Kitty Ng, Elena Belousova, Cheryl M Salome, Jennifer K Peat, Guy B Marks

University of

Sydney, Woolcock

Institute of Medical

Research, Box M77

Missenden Road

Post Office,

Camperdown,

NSW 2050,

Australia

Brett G Toelle

senior research officer,

Kitty $\mathrm{Ng}$

research scientist

Elena Belousova

research scientist

Cheryl M Salome

research fellow

Guy B Marks

honorary associate

professor

Department of

Paediatrics an

Child Health,

University of

Sydney

Jennifer K Peat

associate professor

Address for

correspondence:

B G Toellebgt@

woolcock.org.au

BMJ 2004;328:386-7
We have previously shown that the prevalence of asthma in Australian primary schoolchildren increased substantially between 1982 and $1992 .{ }^{1}$ Similar increases have been reported in studies of children of different ages and from various geographical regions, spanning periods up to the mid-1990s. ${ }^{2}$ It is not known whether this trend has continued during the late 1990s and early 2000s. We therefore conducted a third cross sectional study in the same population that was

surveyed previously. ${ }^{1}$ We report here on prevalence trends over the latter 10 year period.

\section{Participants, methods, and results}

We conducted all studies during June and July in primary schools in and around Belmont, a coastal suburb some $150 \mathrm{~km}$ north of Sydney, Australia. We invited all children in years 3,4 , and 5 (ages 8 - 11 years)

Changes in prevalence of atopy and asthma in primary school children, Belmont, New South Wales, Australia, 1982 to 2002.

Values are numbers (percentages) unless otherwise indicated

\begin{tabular}{|c|c|c|c|c|}
\hline & $\begin{array}{c}1982^{*} \\
(\mathrm{n}=816)\end{array}$ & $\begin{array}{c}1992 \dagger \\
(\mathrm{n}=1052)\end{array}$ & $\begin{array}{c}2002 \dagger \\
(\mathrm{n}=1222)\end{array}$ & $\begin{array}{c}1992 \text { to } 2002 \\
\text { Absolute \% increase (95\% Cl })\end{array}$ \\
\hline Participants (response rate) & $718(88.0)$ & $914(86.9)$ & $810(66.3)$ & \\
\hline Asthma diagnosed & $65 / 718(9.1)$ & $348 / 909(38.3)$ & $249 / 804(31.0)$ & $-7.3 \%(-11.8 \%$ to $-2.8 \%)$ \\
\hline Recent use of asthma medicine & $69 / 718(9.6)$ & $256 / 910(28.1)$ & 185/798 (23.2) & $-4.9 \%(-9.0 \%$ to $-0.8 \%)$ \\
\hline Recent use of inhaled steroids & NA & $112 / 910(12.3)$ & $59 / 591(10.0)$ & $-2.3 \%(-5.5 \%$ to $0.9 \%)$ \\
\hline Wheeze in the past 12 months§ & $75 / 718(10.4)$ & 259/907 (28.6) & $189 / 795(23.7)$ & $-4.9 \%(-9.1 \%$ to $-0.7 \%)$ \\
\hline \multicolumn{5}{|c|}{ No of attacks of wheeze in the past 12 months: } \\
\hline$<4$ & $57 / 718(7.9)$ & $106 / 905(11.7)$ & $80 / 783(10.2)$ & $-1.5 \%(-4.5 \%$ to $1.5 \%)$ \\
\hline$\geq 4$ & $18 / 718(2.5)$ & $144 / 905(15.9)$ & $92 / 783(11.8)$ & $-4.1 \%(-7.4 \%$ to $-0.8 \%)$ \\
\hline Hay fever & $147 / 718(20.5)$ & $310 / 908(34.1)$ & $309 / 804(38.4)$ & $4.3 \%(-0.3 \%$ to $8.9 \%)$ \\
\hline Eczema & $146 / 718(20.3)$ & $222 / 908(24.4)$ & $198 / 800(24.8)$ & $0.4 \%(-3.7 \%$ to $4.5 \%)$ \\
\hline Parental asthma ever & $129 / 718(18.0)$ & 248/891 (27.8) & $218 / 571(38.2)$ & $10.4 \%(5.5 \%$ to $15.4 \%)$ \\
\hline Skin prick test positiveף & & $356 / 906(39.3)$ & $216 / 597(36.2)$ & $-3.1 \%(-8.1 \%$ to $1.9 \%)$ \\
\hline \multicolumn{5}{|l|}{ Airway hyperresponsiveness ${ }^{* *}$} \\
\hline All participants & $65 / 718(9.1)$ & 180/891 (20.2) & $108 / 550$ (19.6) & $-0.6 \%(-4.8 \%$ to $3.6 \%)$ \\
\hline In non-atopic participants & & $40 / 540(7.4)$ & $35 / 353$ (9.9) & $2.5 \%(-1.3 \%$ to $6.3 \%)$ \\
\hline In atopic participants & & $139 / 347(40.1)$ & $71 / 192(37.0)$ & $-3.1 \%(-11.7 \%$ to $5.7 \%)$ \\
\hline Current asthma†† & $32 / 718(4.5)$ & $110 / 889(12.4)$ & $62 / 549(11.3)$ & $-1.1 \%(-4.5 \%$ to $2.3 \%)$ \\
\hline
\end{tabular}

NA=Not available.

${ }^{*}$ Data from ${ }^{3}$ and relating to children aged 8-10 years only.

†Data for children aged 8-11 years in the 1992 and the current (2002) study.

$\ddagger$ Ranges that exclude zero are significant at the $5 \%$ level.

§lncludes a positive response to either wheeze or exercise wheeze in the past 12 months.

IAny allergen skin prick test mean wheal diameter $\geq 3 \mathrm{~mm}$. 1982 data not presented because of methodological differences with 1992 and 2002 data.

**Provoking dose of histamine to cause a $20 \%$ fall in forced expiratory volume at 1 second $<3.91 \mu \mathrm{mol}$.

t†Recent wheeze and airway hyperresponsiveness. 
at selected schools to participate and studied only children who had parental consent. Parents completed a questionnaire about symptoms, diagnosis, and treatment of asthma and other allergic illnesses. We used a histamine challenge test to measure airway hyperresponsiveness and assessed atopy by skin prick tests to house dust, Dermatophagoides farinae, D pterronyssinus, ryegrass, cockroach, cat, Alternaria tenuis (HollistierStier, Spokane, WA, USA). Questionnaires and tests were the same as in 1992. ${ }^{1}$ The data collected in 1982 are not directly comparable because only 8-10 year old children were included and some equipment was different ${ }^{1}$. Owing to a low initial response rate in 2002 a single page anonymous questionnaire was issued to parents who had not consented to their child's participation in the clinical tests. The limited data from this questionnaire have been included.

In 2002 we initially enrolled 627 children (292 $(46.6 \%)$ boys), representing $51.3 \%$ of the eligible sample of 1222. A further 183 participants subsequently provided a questionnaire, yielding an overall sample of 810 children (399 (49.3\%) boys), representing $66 \%$ of the eligible sample. The response rate in 2002 was lower than in previous surveys (table). Between 1992 and 2002 the prevalence of diagnosed asthma, recent wheeze, and use of asthma medication decreased significantly (table). However, the prevalence of hay fever, eczema, atopy, airway hyperresponsiveness, or current asthma (defined as recent wheeze plus airway hyperresponsiveness) did not change significantly. These trends contrast with the substantial rise in the prevalence of most of these indicators during the period 1982 to $1992 .{ }^{1}$

\section{Comment}

These results provide evidence that the trajectory of increasing prevalence of asthma has not continued. A potential limitation is the possibility of selection bias arising from a lower response rate in 2002 compared with 1992. In the 2002 survey the prevalence of asthma symptoms was higher in the initial responders than in the responders in the second phase (data not shown). It seems reasonable to assume that non-responders were more similar to the responders in the second phase than the initial responders, ${ }^{4}$ and some empirical evidence supports this. ${ }^{5}$ If this is the case then the prevalence estimates for 2002 are likely to be overestimates for the population. This direction of potential bias tends to strengthen our conclusion that the prevalence of asthma has not increased further during the period 1992 to 2002.

Although it is good news that the trajectory of increasing asthma prevalence has halted in the locality we studied, it remains to be seen how generalisable and sustained this new trend is. Uncertainty remains about the extent to which fluctuations in asthma prevalence over the past two decades can be attributed to changes in awareness of asthma. The explanation for the reduction in prevalence remains as elusive as the explanation for the initial increase.

Contributors: BGT collected data, conducted data analysis, and wrote the manuscript. KN coordinated the study, collected data and reviewed the manuscript. EB collected data, designed the database, checked accuracy of the data, and reviewed the manuscript. CMS participated in all three surveys, collected data, and reviewed the manuscript. GBM collected data, interpreted the data, and co-wrote the manuscript. JKP assisted with interpretation of the data and reviewed the manuscript.

Funding: Australia Health Management Group.

Competing interests: None declared.

Ethical approval: Human Ethics Committee of the University of Sydney.

1 Peat JK, van den Berg RH, Green WF, Mellis CM, Leeder SR, Woolcock AJ. Changing prevalence of asthma in Australian children. BMJ 1994;308:1591-6.

2 Peat JK, Li J. Reversing the trend: Reducing the prevalence of asthma. J Allergy Clin Immunol 1999;103:1-10

3 Britton WJ, Woolcock AJ, Peat JK, Sedgwick CJ, Lloyd DM, Leeder SR. Prevalence of bronchial hyperresponsiveness in children: the relationship between asthma: the relationship between asthma and skin reactivity to allergens in two communities. Int J Epidemiol 1986;15:202-9.

4 Drane JW. Imputing nonresponses to mail-back questionnaires. Am J Epidemiol 1991;134:908-12.

de Marco R, Verlato G, Zanolin E, Bugiani M, Drane JW. Nonresponse bias in EC respiratory health survey in Italy. Eur Respir J 1994;7:2139-45.

(Accepted 16 October 2003)

\section{One hundred years ago}

\section{Winter holidays}

We have been asked to suggest how and where a medical man could best spend a fortnight's holiday in the month of

February...

We can only suggest what we have done ourselves under the circumstances more than once, and perhaps our suggestion may inspire him with the wish to go and do likewise. It was the end of January last year that we decided to get out of England. We were able to spare just over a fortnight. We had long wished to see Algiers; we took railway and steamer but not hotel tickets from Cook via Dover, Calais, Paris, and Marseilles. As no one in real need of rest would dream of turning their holiday into a time of suffering, we naturally travelled first class, and for those who are fond of railway journeys nothing more delightful can be conceived than sitting in a comfortable carriage, dividing your attention between the scenery and a French novel, if you happen to have found one racy of the soil. The steamers of the Transatlantic Company run in connexion with the Mediterranean express trains, and Algiers is reached some fifty hours after leaving London...
Did he wish for gaiety, we would advise our inquiring colleague to go as fast as he could to Monte Carlo from London by the Mediterranée Sud Express; he would be there in twenty-four hours. Once there he should take up his quarters in a room with balconied windows facing the Casino and the sea. Surely with ten days spent between the Casino with its rooms and theatre, where there are generally in February some of the best Paris companies, varied by excursions, what more could heart of man desire?

Then there is Constantinople, that wondrous city which to see once is to long to see again and again; it exercises a sort of subtle fascination on any one with a soul. A halt of twenty-four hours may be made at Vienna, which is reached in about thirty hours (travelling via Ostend by the Orient express). There there are delightful shops, theatres, and drives. At Buda-Pesth, about five hours further on, another halt may be made, our friend leaving it probably a merrier, but a poorer, man.

(BMJ 1904;i:29) 